\title{
Productivity Testing and Analysis of Low Permeability and Thick Layer of N Gas Field
}

\author{
Huang QuanHua ${ }^{1}$, Lin XingYu ${ }^{1, *}$, Yang Zhi-xing ${ }^{2}$, Lu Ke-feng ${ }^{2}, \mathrm{Hu}$ Xian-kang ${ }^{1}$ \\ 1.Petroleum engineering school, Southwest petroleum university, Chengdu, Sichuan, 610500, china \\ ${ }^{2}$ CNOOC Shanghai Branch,Shanghai,20050, china
}

\begin{abstract}
For a better guidance of production, a combination of drill stem testing (DST), regional statistical method and pseudo steady-state seepage theory model was used to analyze the productivity of $\mathrm{N}$ gas reservoir in light of the complex geological features of the low-permeability thick-layer. Firstly, the DST method was used to test the $\mathrm{N}$ gas reservoir. And then the binomial pseudo-pressure method, binomial pressure square method and exponential method were used to interpret the test data of DST of this formation. Finally, the binomial pseudo-pressure interpretation method was used and the results showed that only the productivity of $\mathrm{H} 3 \mathrm{~b}$ layer was successfully tested of the four. The H3a, H4b and H5a layers are ultra-low pore and permeability gas reservoirs and the productivity of these layers can't be explained by the available data due to the short testing time and a non-stationary state of testing pressure and quantity, resulting in the failure of the test. The productivity of the main layers were estimated and forecasted by the regional statistical method and the theoretical model of pseudo steady-state seepage, taking the arithmetic average value of the regional statistical method and the theoretical formula as the final value of absolute open flow rates(AOF). The final calculation results are as follows: the AOF of main gas layers $\mathrm{H} 3 \mathrm{a}, \mathrm{H} 3 \mathrm{~b}, \mathrm{H} 4 \mathrm{~b}$ and $\mathrm{H} 5 \mathrm{a}$ in $\mathrm{N}$ gas field is $31.30 \times 10^{4} \mathrm{~m}^{3} / \mathrm{d}, 388.92 \times 10^{4} \mathrm{~m}^{3} / \mathrm{d}, 20.82 \times 10^{4} \mathrm{~m}^{3} / \mathrm{d}$ and $30.80 \times 10^{4} \mathrm{~m}^{3} / \mathrm{d}$, respectively. This method may sheds light on verifying and calculating the productivity of gas wells and determining the reasonable production allocation of gas wells.
\end{abstract}

\section{Introduction}

The low-permeability gas reservoirs in China are rich in resources and have great development potential. At present, many scholars at home and abroad have conducted corresponding research on the production capacity prediction of low permeability gas reservoirs.

DST is a work aiming at obtaining the parameters of the oil and gas layer under dynamic conditions, evaluating the oil and gas layer timely and accurately after encountering the oil and gas display in the process of drilling to obtain a temporary completion test for reservoirs. DST is commonly used in Productivity prediction because of the characteristics of reducing drilling cost, improving oil testing speed and discovering oil and gas layers in time. Due to its limited self-spraying capacity, DST is generally applied to medium-high permeability gas reservoirs rather than low permeability ones ${ }^{[2]}$. However, with the development of technology, DST has been successfully applied in conventional oil and gas reservoirs, high temperature and high pressure oil and gas reservoirs ${ }^{[3-5]}$, coalbed methane reservoirs ${ }^{[6-7]}$, high sulfur gas reservoirs and low permeability tight sandstone oil and gas reservoirs ${ }^{[8-12]}$, and achieved good results. $\mathrm{N}$ gas field is a low-permeability gas field with strong heterogeneity. During the production process, multiple DSTs were carried out.

The regional statistical is a method to regression the statistical samples and obtain the relationship between the unit thickness absolute open flow rate and the log permeability using more relevant gas reservoir productivity test data ${ }^{[13-14]}$, which is often used in the absence of data or in the case of insufficient data. This paper combines the productivity test data of typical lowpermeability gas fields to predict the productivity of $\mathrm{N}$ gas field.

The seepage theory model is derived by the formula method, which refers to using the principle of seepage mechanics, considering the seepage characteristics of gas reservoir, and using the relevant productivity formula to calculate. In terms of the production characteristics of $\mathrm{N}$ thick gas reservoirs, due to the degree of gas well opening, skin effect in the near wellbore zone and the non-Darcy effect on productivity, productivity cannot be evaluated

*Corresponding author: cnlinxingyu@163.com 
by a single plane radial flow or ball-to-heart flow capacity equation. So we use a pseudo steady-state productivity equation combining plane radial flow and ball-oriented flow, and the result is more in line with the actual ${ }^{[15-18]}$.

$\mathrm{N}$ gas reservoir is a heterogeneous gas reservoir with low permeability and thick layers, and the gas reservoir is not fully open, some gas Wells have carried out stimulation operations, and the productivity is difficult to predict. Therefore, single productivity prediction method is not good enough. Through the combination of various methods, optimization is carried out to finally determine the productivity of different production layers ${ }^{[19]}$.

\section{Productivity test}

Table 1 DST statistics for N gas field.

\begin{tabular}{|c|c|c|c|c|c|c|}
\hline Well No & Test number & Test layer & $\begin{array}{l}\text { Original formation } \\
\text { pressure }\end{array}$ & $\begin{array}{l}\text { Whether it is } \\
\text { representative } \\
\text { productivity data }\end{array}$ & $\begin{array}{l}\text { Test failure } \\
\text { reason }\end{array}$ & $\begin{array}{l}\text { Whether it is } \\
\text { main layer }\end{array}$ \\
\hline \multirow{4}{*}{ N1 } & DST1 & Under $\mathrm{H} 3 \mathrm{~b}$ & Measured & Yes & I & Yes \\
\hline & DST2 & upper H3b & Measured & Yes & / & Yes \\
\hline & DST3 & $\mathrm{H} 2 \mathrm{c}$ & $\begin{array}{c}\text { Maximum } \\
\text { recovery pressure }\end{array}$ & No & $\begin{array}{l}\text { Not } \\
\text { tested }\end{array}$ & No \\
\hline & DST4 & H1a & Measured & No & \multirow{6}{*}{$\begin{array}{l}\text { Test time } \\
\text { is short, } \\
\text { pressure and } \\
\text { flow are not } \\
\text { stable }\end{array}$} & No \\
\hline N2 & DST2 & H5a & Measured & No & & Yes \\
\hline \multirow{3}{*}{ N3 } & DST1 & $\mathrm{H} 4 \mathrm{~b}$ & $\begin{array}{c}\text { Maximum } \\
\text { recovery pressure }\end{array}$ & No & & Yes \\
\hline & DST1A & $\mathrm{H} 4 \mathrm{~b}$ & Not tested & No & & Yes \\
\hline & DST2 & $\mathrm{H} 3 \mathrm{a}$ & Measured & No & & Yes \\
\hline N4 & DST1 & $\mathrm{H} 4 \mathrm{~b}$ & Measured & No & & Yes \\
\hline
\end{tabular}

From June 4th to June 11th, 2013, the DST was applied to N1 well on the upper H3b layer (the depth of the perforation section is $3709 \mathrm{~m}-3739 \mathrm{~m}$ ), and the gas test results are shown in table 2 . The binomial pseudopressure method, binomial pressure plane method and

\subsection{DST}

In the $\mathrm{N}$ gas field, eight DSTs have been carried out for six layers including H1a, H2c, H3a, H3b, H4b and H5a, which were tested by four wells. Four DSTs have been carried out for N1 well, including lower $\mathrm{H} 3 \mathrm{~B}$ layer, upper H3B layer, H2C layer and H1a layer; One DST has been carried out for N2 well, with H5a layer; Two DSTs have been carried out for $\mathrm{N} 3$ well, with $\mathrm{H} 4 \mathrm{~b}$ layer and $\mathrm{H} 3 \mathrm{a}$ layer; One DST has been carried out for N4 well, with H4b layer. According to the DST profile of each well, representative productivity test data were obtained in five of the nine tests. The following table explains and analyzes the productivity of the main layer for representative test data.

Table 2 Test results of the upper H3b layer in N1 well

\begin{tabular}{|c|c|c|c|c|}
\hline Level number & Perforated interval, $\mathrm{m}$ & $\mathrm{Pi}, \mathrm{MPa}$ & Pwf, MPa & Daily productivity, $10^{4} \mathrm{~m}^{3}$ \\
\hline \multirow{4}{*}{ Upper H3b } & \multirow{4}{*}{$3709-3739$} & \multirow{4}{*}{36.84} & 34.05 & 10.041 \\
\hline & & & 28.26 & 24.4974 \\
\hline & & & 23.2 & 36.2298 \\
\hline & & & 21.58 & 39.3198 \\
\hline
\end{tabular}




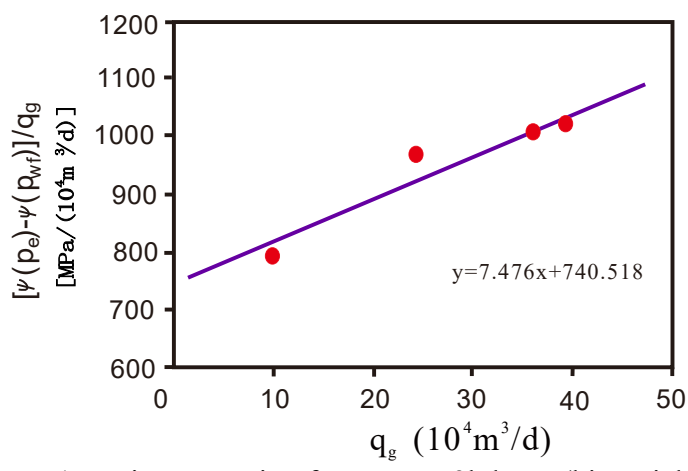

Figure1 test interpretation for upper H3b layer (binomial

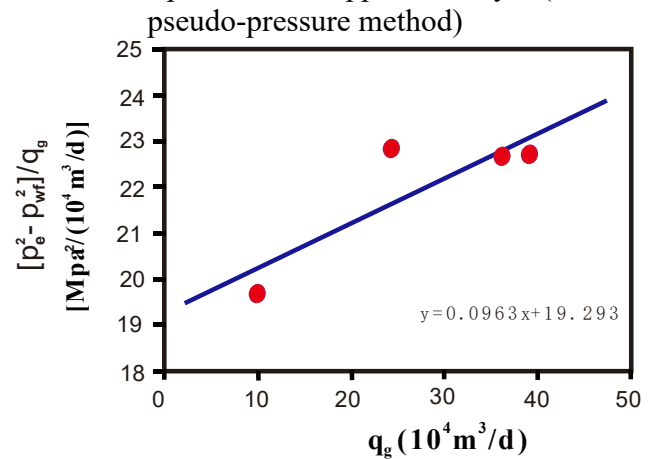

Figure2 test interpretation for upper H3b layer (binomial pressure flat method)

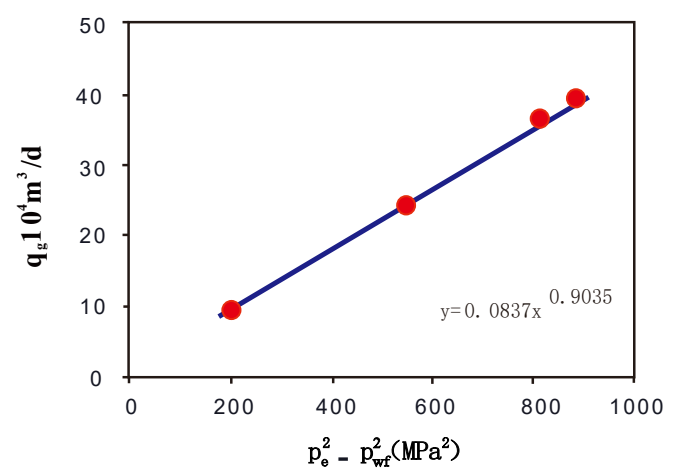

Figure3 test interpretation for upper H3b layer (exponential

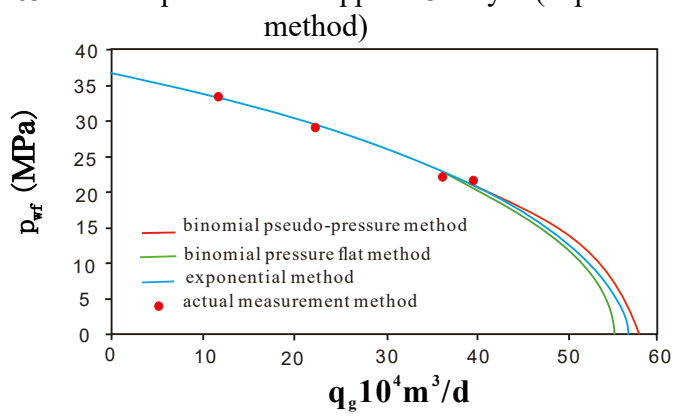

Figure4 IPR curve in the upper H3b layer

From May 21st to June 3rd, 2013, the DST was applied to N1 well on the lower H3b layer (the depth of the perforation section was $3769 \mathrm{~m}-3799 \mathrm{~m}$ ), and the gas test results are shown in table3. The binomial pseudopressure method, binomial pressure plane method and exponential method were respectively adopted to interpret the DST data too. The results are shown in Figure5 figure7 are the gas test interpretation result curves of different methods, and the IPR curve is shown in Figure8.

Table3 Test results of the lower H3b layer in N1 well

\begin{tabular}{|c|c|c|c|c|}
\hline $\begin{array}{l}\text { Level } \\
\text { number }\end{array}$ & $\begin{array}{l}\text { Perforated } \\
\text { interval, } m\end{array}$ & $\begin{array}{l}\mathrm{Pi} \\
\mathrm{MPa}\end{array}$ & $\begin{array}{l}\text { Pwf, } \\
\mathrm{MPa}\end{array}$ & $\begin{array}{l}\text { Daily production } \\
\text { capacity, } 10^{4} \mathrm{~m}^{3}\end{array}$ \\
\hline \multirow{6}{*}{$\begin{array}{l}\text { Lower } \\
\mathrm{H} 3 \mathrm{~b}\end{array}$} & \multirow{6}{*}{$\begin{array}{l}3769.0 \sim \\
3799.0\end{array}$} & \multirow{6}{*}{36.947} & 36.02 & 19.9814 \\
\hline & & & 35.57 & 28.1341 \\
\hline & & & 34.99 & 41.0598 \\
\hline & & & 34.35 & 54.4824 \\
\hline & & & 36.48 & 10.8058 \\
\hline & & & 34.54 & 53.5364 \\
\hline
\end{tabular}




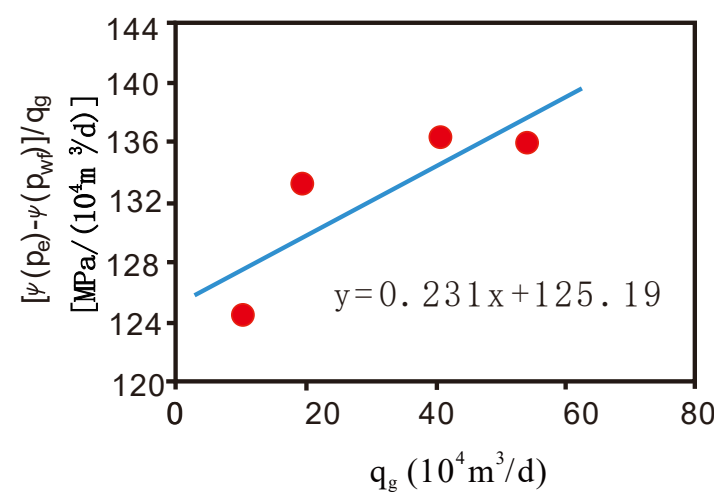

Figure5 test interpretation for lower H3b layer (binomial pseudo-pressure method)

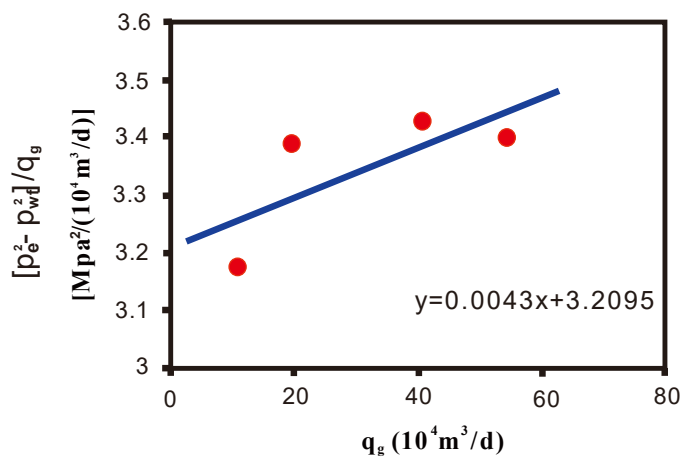

Figure6 test interpretation for lower H3b layer (binomial

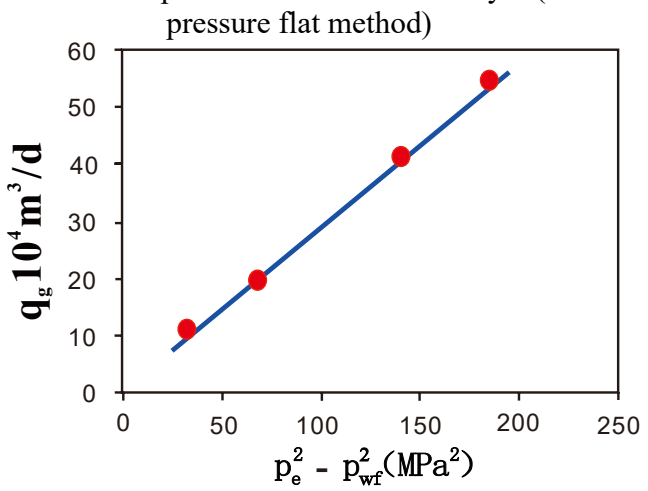

Figure7 test interpretation for lower $\mathrm{H} 3 \mathrm{~b}$ layer (exponential

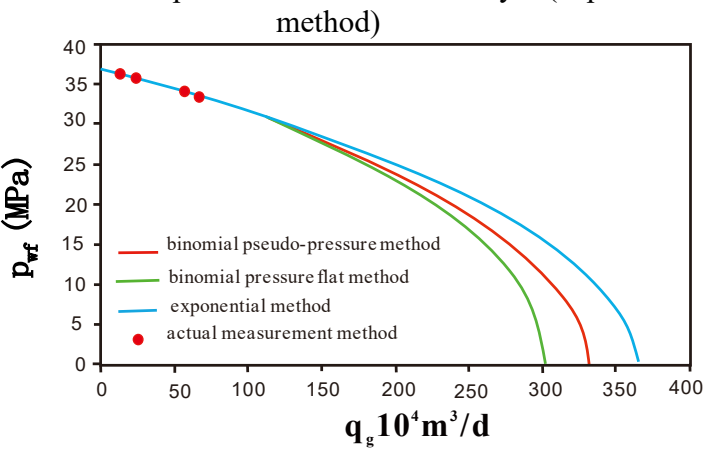

Figure8 IPR curve in the lower H3b layer

It can be seen from the table that there is a difference in the AOF obtained by different methods. In view of the fact that the binomial pseudo-pressure interpretation method is based on the gas seepage theory, the interpretation results have a high degree of confidence. So the ultimate AOF on the upper $\mathrm{H} 3 \mathrm{~b}$ layer and lower $\mathrm{H} 3 \mathrm{~b}$ layer of the $\mathrm{N} 1$ well is calculated by the pseudopressure interpretation method. The AOF on the upper $\mathrm{H} 3 \mathrm{~b}$ layer and lower H3b layer is $57.38 \times 104 \mathrm{~m} 3 / \mathrm{d}$, $331.06 \times 104 \mathrm{~m} 3 / \mathrm{d}$.

\subsection{Regional Statistics Method}

Only the H3b layer has been successfully tested for productivity with DST in the upper section of the Huagang formation of $\mathrm{N}$ gas field. Due to the ultra-low characteristics of porosity and permeability of $\mathrm{H} 3 \mathrm{a}, \mathrm{H} 4 \mathrm{~b}$ and H5a layers and the short test time, the pressure and output have not reached a stable state, and the existing data cannot explain the productivity of these layers, resulting in the failure of the test.

The regional statistical method and the pseudo steadystate seepage theory model were used to estimate and predict the productivity of the untested main layer $(\mathrm{H} 3 \mathrm{a}$ layer and H4b layer of N3 well, H5a layer of N4 well).

Example of the method: Based on the method of DST, the statistical relationship between AOF and logging permeability for $\mathrm{H} 3 \mathrm{~B}$ of $\mathrm{N}$ gas field is as follows (as figure 9):

$$
q_{\text {AOF }}=0.743 \times K h+0.3524 \times h
$$

Due to the small number of samples, the statistical formula should not be directly used for productivity prediction. Therefore, combining the productivity test data of typical low permeability gas fields in China, including Yanchang field, Yulin gas field, Sulige gas field and Daniudi gas field, etc. The relationship between the AOF of per unit thickness and the log permeability with a larger statistical sample size:

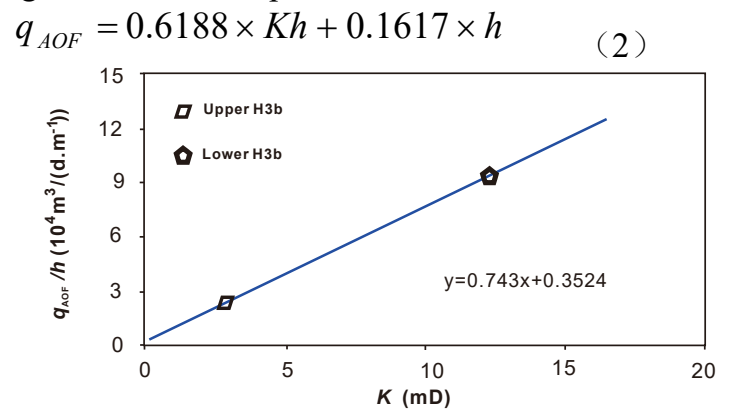

Figure9 $\mathrm{q}_{\mathrm{AOF}} / \mathrm{h} \sim \mathrm{K}$ statistical relationship curve

Using the regression regional statistical formula (Equation3), the productivity of the untested main gas layer in the $\mathrm{N}$ gas field predicted is $23.84 \sim 30.12 \times 104 \mathrm{~m} 3 / \mathrm{d}$. The specific results are shown in the table4.

Table 4 Results of regional statistical method for predicting the productivity of the main layer

\begin{tabular}{|r|c|c|c|}
\hline Layer & Thickness, $\mathrm{m}$ & Permeability, $\mathrm{mD}$ & $\mathrm{AOF}, 10^{4} \mathrm{~m}^{3} / \mathrm{d}$ \\
\hline H3a & 31.8 & 1.14 & 27.57 \\
\hline H4b & 57.4 & 0.41 & 23.84 \\
\hline H5a & 62.3 & 0.52 & 30.12 \\
\hline
\end{tabular}




\subsection{Capacity test of pseudo steady-state seepage theory model}

For N-thick gas reservoirs with heterogeneous, the opening degree is not perfect. According to the principle of seepage mechanics and considering the seepage characteristics in the wells, the calculation formula of productivity is established. The model diagram is as Figure10.

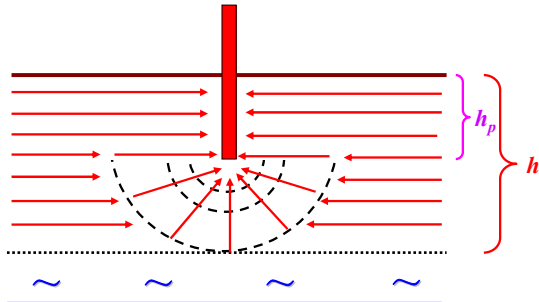

Figure10 Seepage diagram of Wells with imperfect opening degree of thick reservoir

For the opening layers, the productivity formula of the plane radial flow considering the skin effect and the nonDarcy flow characteristics is derived according to the gas pseudo-stabilized seepage theory. In the vertical region of $\mathrm{hp}$, the binomial equation of the plane radial flow is as follows:

$$
\begin{aligned}
& p_{e}^{2}-p_{w f}^{2}=\frac{1.291 \times 10^{-3} T Z \mu}{K h_{\mathrm{p}}} D_{1} q_{s c 1}^{2}+\frac{1.291 \times 10^{-3} T \mu Z}{K h_{p}}\left(\ln \frac{0.472 r_{e}}{r_{w}}+S\right) q_{s c 1} \\
& D_{1}=2.191 \times 10^{-18} \frac{\beta \gamma_{\mathrm{g}} K}{\mu h_{\mathrm{p}} r_{\mathrm{w}}}
\end{aligned}
$$

For some layers that are not opened (Zone ${ }^{h-h_{\mathrm{p}}}$ ), in the vicinity of the wellbore, the form of the spherical centripetal flow and the plane radial flow are combined. According to the pseudo steady-state seepage theory, the spherical centripetal flow productivity formula considering the formation pollution and the non-Darcy flow is derived. There is the binomial equation as follows:

$$
\begin{aligned}
& p_{e}^{2}-p_{w f}^{2}=\frac{1.291 \times 10^{-3} Z \mu T}{K r_{\mathrm{w}}} D_{2} q_{s c 2}^{2}+1.291 \times 10^{-3} Z \mu T \\
& {\left[\frac{1}{K r_{\mathrm{w}}}\left(1-\frac{9}{5} \frac{r_{w}}{h-h_{p}}+S_{1}\right)+\frac{1}{K\left(h-h_{p}\right)} \ln \frac{0.472 r_{e}}{h-h_{p}}\right]} \\
& D_{2}=7.032 \times 10^{-19} \frac{\beta \gamma_{\mathrm{g}} K}{\mu}\left(\frac{1}{r_{\mathrm{w}}^{2}}-\frac{r_{\mathrm{w}}}{\left(h-h_{\mathrm{p}}\right)^{3}}\right)
\end{aligned}
$$

Where:h-thickness of gas layer, m;qsc1-gas production in standard state, $\mathrm{m} 3 / \mathrm{d} ; \mathrm{K}-$ effective permeability, $\mathrm{mD}$; $\mathrm{u}-$ gas viscosity, $\mathrm{mPa} \cdot \mathrm{s} ; \mathrm{Z}-\mathrm{Z}$ factor; $\mathrm{T}$ - gas layer temperature, K;hp - opening thickness of gas layer, m; rw-wellbore radius, m;D turbulence coefficient;re-drainage radius, $\mathrm{m} ; \mathrm{Pe}-$ formation pressure, $\mathrm{MPa} ; \mathrm{Pwf}$ - bottomhole pressure $(\mathrm{MPa}) ; \beta$-velocity coefficient, $\beta=7.644 \times 10^{10} / K_{\mathrm{s}}^{1.5}$, $\mathrm{m}^{-1} ; \mathrm{S}$-skin coefficient; ${ }^{\gamma_{g}}$ — relative density.

For the thick gas reservoir partially opened, the plane radial flow and the spherical centripetal flow simultaneously exist, so the total gas production qsc in the gas well is the sum of the gas flows under the two seepage conditions:

$$
q_{s c}=q_{s c 1}+q_{s c 2}
$$

Based on the established pseudo steady-state seepage theory model ,the AOF of main layers H3a, H4b and H5a in $\mathrm{N}$ gas field is $21.28 \sim 27.912 \times 104 \mathrm{~m} 3 / \mathrm{d}$, as shown in the following table.

Table5 the productivity predicting results of $\mathrm{N}$ gas field

\begin{tabular}{|c|c|c|c|c|c|c|c|c|c|}
\hline Parameter & $\begin{array}{c}\mathrm{H} \\
(\mathrm{m})\end{array}$ & $\begin{array}{c}\mathrm{K} \\
(\mathrm{mD})\end{array}$ & $\begin{array}{c}\mathrm{p}_{\mathrm{e}} \\
(\mathrm{MPa})\end{array}$ & $\begin{array}{c}\mathrm{T} \\
(\mathrm{K})\end{array}$ & $\boldsymbol{\gamma}_{\mathrm{g}}$ & $\begin{array}{c}\mu \\
\left(\mathrm{mPa.s} \_\right.\end{array}$ & $\begin{array}{c}\mathrm{r}_{\mathrm{w}} \\
(\mathrm{m})\end{array}$ & $\begin{array}{c}\mathrm{r}_{\mathrm{e}} \\
(\mathrm{m})\end{array}$ & $\begin{array}{c}\mathrm{q}_{\mathrm{AOF}} \\
\left(10^{4} \mathrm{~m} / \mathrm{d}^{3}\right)\end{array}$ \\
\hline H3a & 31.8 & 1.14 & 36.64 & 421.3 & 0.615 & 0.025 & 0.1015 & 500 & 35.03 \\
\hline H4b & 57.4 & 0.41 & 45.57 & 437.5 & 0.615 & 0.028 & 0.1015 & 500 & 17.8 \\
\hline H5a & 62.3 & 0.52 & 53.99 & 446 & 0.615 & 0.030 & 0.1015 & 500 & 31.49 \\
\hline
\end{tabular}

\section{Result analysis}

\begin{tabular}{|c|c|c|c|c|}
\hline \multirow[b]{2}{*}{ Layer } & \multicolumn{4}{|c|}{ Unit: $10^{4} \mathrm{~m} / \mathrm{d}^{3}$} \\
\hline & DST & $\begin{array}{l}\text { Regional statistical } \\
\text { formula }\end{array}$ & $\begin{array}{c}\text { Pseudo steady- } \\
\text { state seepage theory } \\
\text { model }\end{array}$ & The values \\
\hline $\mathrm{H} 3 \mathrm{a}$ & & 27.57 & 35.03 & 31.30 \\
\hline Upper H3b & 57.38 & & & 57.38 \\
\hline Lower H3b & 331.54 & & & 331.54 \\
\hline $\mathrm{H} 4 \mathrm{~b}$ & & 23.84 & 17.80 & 20.82 \\
\hline
\end{tabular}

Regarding the final value of the productivity of each main gas layer in the gas field, the following principles are applied:

First, for the gas layer with DST data, as far as

Table6 Summary of AOF of various gas layers in $\mathrm{N}$ gas field possible, the results of the DST shall prevail;

Second, for the gas layer without DST, the arithmetic mean of the results calculated by the regional statistical method and the theoretical formula is taken as the final value of the AOF.

Based on the two principles above, the AOF of each gas layer in $\mathrm{N}$ gas field is determined as follows (table 6): 
It can be seen from Table 8 that the AOF of the main gas layers $\mathrm{H} 3 \mathrm{a}, \mathrm{H} 3 \mathrm{~b}$ (including upper $\mathrm{H} 3 \mathrm{~b}$ and lower $\mathrm{H} 3 \mathrm{~b}$ ), $\mathrm{H} 4 \mathrm{~b}$ and $\mathrm{H} 5 \mathrm{a}$ of the $\mathrm{N}$ gas field are $31.30 \times 104 \mathrm{~m} 3 / \mathrm{d}$, $388.92 \times 104 \mathrm{~m} 3 / \mathrm{d}, 20.82 \times 104 \mathrm{~m} 3 / \mathrm{d}$ and $30.80 \times 104 \mathrm{~m} 3 / \mathrm{d}$.

\section{Conclusion}

(1) Using DST, regional statistical method and pseudo steady-state seepage theory model to evaluate the productivity of $\mathrm{N}$ low- permeability gas reservoir. The method is simple and practical, less time consuming and low cost. With the comparing of a variety of methods, the results are reliable and easy to promote.

(2) For thick heterogeneous gas reservoirs, it is not possible to simply use single plane radial flow or spherical centripetal flow to evaluate the productivity. For the opening part of the layer, it is regarded as plane radial flow. For some layers that are not open, it is regarded as spherical centripetal flow. The pseudo steadystate seepage theory model is adopted to superimpose the productivity of the two, and the calculation results are more consistent with the actual production situation.

(3) When using the DST to evaluate the productivity of the gas well, the AOF explained by the binomial pseudo-pressure method is more reliable ; For the gas well that cannot be explained by the DST, when the regional statistical method is used for evaluation, In addition to the hole-permeability-saturated relationship fitted by the DST method, it is also necessary to find more productivity test data of gas wells with similar properties, and to regress the relationship between the AOF and the permeability to ensure its practicability; The pseudo steady-state seepage theory model should satisfy the actual geological conditions and seepage conditions as much as possible, and select the appropriate seepage equation to solve.

\section{Acknowledgments}

Supported by the National Major Science and Technology Project "Research on percolation Mechanism and Development Technology Policy of Thick Heterogeneous Gas Reservoirs" (No. :2016ZX05027004-005).

\section{Reference}

1. Zhou Y M, Tao G Li X Y.(2008) Application progress of cable formation testing technology. Science and technology review, 15:89-92.

2. Liu B, Chang T, Qu B C, et al.(2019)DST productivity correction method based on well test technology. Petroleum drilling \& production technology, 41(01):83-88.

3. Yang erdong.(2018) Reliability and effectiveness of DST tool in high temperature and high pressure well test. Management and technology of small and medium-sized enterprises, 08:171-172.

4. Zhang $\mathrm{H} \mathrm{W}$, Zheng D H, Ling W E.(2017) Calculation of bottom hole flow pressure and wellhead backpressure in high temperature and high pressure production Wells DST. Science, technology and engineering,17(23):179-183.

5. Ren C Q, Li W H, Yang L, Xiang Y Q, Wang S C, et al. ( 20170 ) Application of mini-DST and interpretation technology in offshore lowpermeability exploration Wells. Oil and gas well test, 26(06):29-31+74.

6. Liu C Y.(2017)Application of DST technology in CBM parameter Wells. China new technology and new products, 21:14-15.

7. Cheng W P, Li J, Cheng M.(2018)Application of DST well test technology in unconventional natural gas reservoirs in coal measures . China coal geology, 30(04):29-32+44.

8. Du J ,Mo A G, Lei Q, Zhou C, Pang W. (20190Low permeability tight gas Wells DST interpretation Daqing petroleum geology and development: 1-7.

9. Wang Q H, Feng J. Guan Y,et al. (2019)Permeability logging evaluation method for low porosity and low permeability sandstone reservoirs based on dynamic data - a case study of paleogene system in LuFeng sag. Acta petroleum sinica, 40(S1):206-216.

10. Hou Z. (2018)Injectivity and effectiveness of polymer flooding in low permeability reservoirs. Southwest petroleum university.

11. Le H M. (2018)Interpretation and evaluation of TCPDST data in well 140 of DongSheng gas field . Neijiang science and technology, 39(07):72+97.

12. Liao H J, Yang Z X, Lu K F, Cheng C,et al . (2018) Study on productivity evaluation technology for water drive gas reservoirs over the whole life cycle . Journal of Yangtze university,15(03):64-69+7.

13. Tong K J, Shan Y M. (2008)Reservoir productivity classification prediction based on statistics. Natural gas exploration and development, (02):40-43+80.

14. Chen Y Q. (1998)Practical oil and gas reservoir engineering methods [. University of petroleum pres.

15. Zhu Y D.(1990) Spherical flow well test analysis method. Oil and gas well test, (03):26-33.

16. Wang X D, Zhang Q B, Zou Y H.(2005) Skin factor and seepage pattern. Oil and gas well test,(02):1$3+74$.

17. Huang Q H, Tong K, Chen C, et al. (2017)Study on quasi-steady productivity of gas Wells in thick gas reservoirs. Lithologic oil and gas reservoirs,29(06):148-153.

18. Chen Y Q, Sun B, Jiang F G, et al. (2009) Derivation and application of production formula for 
hemispherical flow gas well . Oil and gas well test, 18(03):1-4+75.

19. Xu L Q, li X S.( 2005) Comparative analysis of different productivity evaluation methods. Oil and gas well test, (06):15-17+72-73. 